\title{
Modular design of highly active unitized reversible fuel cell electrocatalysts
}

\author{
Malte Klingenhof, ${ }^{1}$ Philipp Hauke, ${ }^{1}$ Sven Brückner, ${ }^{1}$ Sören Dresp, ${ }^{1}$ Elisabeth Wolf, ${ }^{2}$ Hong Nhan Nong,,${ }^{1,3}$ \\ Camillo Spöri, ${ }^{1}$ Thomas Merzdorf, ${ }^{1}$ Denis Bernsmeier, ${ }^{1}$ Detre Teschner, ${ }^{2,3}$ Robert Schlögl, ${ }^{2,3}$ Peter \\ Strasser $^{1 *}$
}

1. The Electrochemical Energy, Catalysis, and Materials Science Laboratory, Department of Chemistry, Chemical Engineering Division, Technical University Berlin, Berlin, Germany

2. Fritz Haber Institute of the Max Planck Society, Department of Inorganic Chemistry, Faradayweg 4, D-14195 Berlin, Germany

3. Max Planck Institute for Chemical Energy Conversion, Department of Heterogeneous Reactions, Stiftstr. 34-36, D-45470, Mülheim an der Ruhr, Germany

*Corresponding author:

Peter Strasser, email: pstrasser@tu-berlin.de 


\section{Abstract}

A modular, multi-component catalyst design principle is introduced and exemplified using a threecomponent, ORR/OER catalyst designed for the oxygen electrode of unitized reversible fuel cells (URFCs). The catalyst system exhibited unprecedented catalytic performance in liquid electrolyte and in single unitized reversible fuel cell tests. The distinct components, each active for either ORR OER are prepared and optimized independently of each other and physically mixed during electrode preparation. The new modular URFC catalyst, $\mathrm{Cu}-\alpha-\mathrm{MnO}_{2} / \mathrm{XC}-72 \mathrm{R} / \mathrm{NiFe}-\mathrm{LDH}$, combined a carbon-supported, $\mathrm{Cu}$-stabilized $\alpha$ $\mathrm{MnO}_{2}$ ORR catalyst with a NiFe-LDH OER catalyst and displayed improved activity and stability under URFC cycling compared to platinum group metal references. Stepwise modular optimization of the carbon and the interlayer anions of the OER component led to a further improved derivative, $\mathrm{Cu}-\alpha-\mathrm{MnO}_{2} / \mathrm{O}-$ MWCNTs/NiFe-LDH-Cl- This URFC catalyst outperformed all previous materials in terms of its combined overpotential $\eta_{\mathrm{ORR} \text {-OER }}$ and performance stability in RDE scale. Its single cell performance is analyzed and discussed. 
Dwindling fossil raw materials and the ongoing climate change require development of concepts based on renewable energies sources (RES) competing with fossil fuel-based technologies (oil, coal, gas). Changing from fossil fuel-based energy system to an energy system based on RES, such as wind or solar power plants, requires flexible large-scale energy storage capacities and on-demand provider technologies. Hydrogen due to high gravimetric energy density is a predestinated energy carrier molecule. In addition to its present industrial applications in fertilizer production, syn-gas chemistry to make methanol or liquid fuels using the Fischer-Tropsch process, hydrogen is a top candidate as an energy vector and renewable energy storage molecule. Using water electrolysis (WE), green hydrogen can be produced using surplus electricity provided by RES. ${ }^{1}$ Mobile and stationary Fuel Cells (FC) reconvert green hydrogen into electrical energy and water. Together, WE and FC constitute a closed chemistry and energy cycle.

Combining WE and FC functions into one device is what is known as a regenerative hydrogen/oxygen fuel cell (RFC). The most compact RFC design is the unitized regenerative fuel cell (URFC), which consists of a single stack, in which the oxygen (positive) and hydrogen (negative) electrodes are intermittently used to catalyze the Oxygen Evolution Reaction (OER) and Hydrogen Evolution Reaction or the Oxygen Reduction Reaction (ORR) and Hydrogen Oxidation Reaction. In other words, the electrodes act intermittently as anode or cathode depending on the mode of operation. URFCs offer a promising compact concept for conversion, storage and supply of renewable electricity. The compact design affords lower material costs, lower weight and volume, ideal for applications in remote areas or confined spaces.

In practice, however, the kinetically sluggish multi-electron processes, in particular ORR and OER at the oxygen electrode, require large overpotentials. ${ }^{2,3}$ The overpotentials between ORR and OER result in wide potential gaps between the onset potentials of ORR and OER, which is why catalysts suffer from efficiency losses as well as degradation during intermittent fuel cell and water electrolysis operation. Especially carbon containing catalysts suffer from degradation mechanisms at significant levels at potentials above $1.3 \mathrm{~V}$ vs RHE. ${ }^{4-6}$ Furthermore, OER and ORR require different families of chemical catalysts making the successful search for a single catalyst with a single type of active site for both reactions unlikely. An alternative URFC catalyst design principle comprises a modular two-or more component bi-functional OER/ORR catalyst for URFCs. The key stipulation of a modular design is that the distinct catalyst components should be catalytically active and stable in their respective operation mode and electrode potential range. Another, equally important requirement, however, is that each catalyst component must remain stable under the respective reverse operation mode and potential range, and must not inhibit the operation of the other catalyst components. Indeed, it is the retention of performance under sustained intermittent switching between FC and WE operation that poses the key challenge for multi-component URFC catalysts. A number of previous publications have reported URFC oxygen catalysts with sufficient "one-way" reactivity for either ORR or OER. ${ }^{7-14}$ However, all these catalysts proved impractical under sustained alternating 
operation conditions due to severe degradation, agglomeration, carbon corrosion or site detachment, affecting especially the ORR active sites. ${ }^{15-17}$ To date, no multi-component bi-functional URFC electrocatalyst has ever exhibited satisfactory long-term stabilities under alternating OER and ORR operation at technologically relevant current densities nor has described a promising preparation method for suitable bi-functional system. Our contribution offers an auspicious approach for the design and assembly of active and stable bi-functional oxygen electrodes.

We present a new three-component, bi-functional Platinum Metal Group (PGM)-free OER/ORR electrocatalyst design optimized for intermittent URFC operation. To avoid PGM components, ${ }^{18,19} 20$ the catalytic active components of the catalyst rely exclusively on transition metal oxides (TMOs). ${ }^{7,21-23}$ NickelIron layered double hydroxides (NiFe-LDH) are employed as the OER catalyst component. ${ }^{7,24,25}$ The ORRactive catalyst component - unlike in previous reports - was neither based on any type of metal-doped single metal atom carbon-based material, ${ }^{7,26}$ nor the widely popular redox active $\gamma-\mathrm{MnO}_{2},{ }^{25}$ which both severely lacking chemical stability under OER operation cycles or competitive ORR activity. We discovered that supported, Cu-stabilized, Cryptomelane-type $\alpha-\mathrm{MnO}_{2}$ overcomes the shortcomings of previous ORR catalyst components. Combining the $\mathrm{NiFe}-\mathrm{LDH}$ phase and the $\mathrm{Cu}-\alpha-\mathrm{MnO}_{2}$ phase physically in a liquid ink with a conductive support in form of a three-component catalyst yields URFC oxygen electrodes with previously unachieved bi-functional ORR and OER performance and stability in $0.1 \mathrm{M} \mathrm{KOH}$. Built from independently prepared and optimized components, the present catalyst design has a quite flexible modular character, which may allow further tuning of individual functionality. 


\section{Catalyst preparation and physicochemical characterization}

The bi-functional catalyst system consists of two independently prepared catalytically active components, that is NiFe-LDH as OER-active component and $\mathrm{Cu}-\alpha-\mathrm{MnO}_{2}$ as ORR catalyst, as well as a carbonaceous component, such as commercial $\mathrm{XC}-72 \mathrm{R}$ or oxidized multi walled carbon nanotubes (O-MWCNT) as conductive support component. For the preparation of NiFe-LDH a microwave assisted one-pot synthesis route was used (Figure $1 \mathrm{a}$ ). ${ }^{7}$ Modifications of NiFe-LDH are based on a protocol reported by Song et al.. ${ }^{27}$ $\mathrm{Cu}-\alpha-\mathrm{MnO}_{2}$, was prepared based on a solvent free Top-Down approach (Figure 1 b). ${ }^{28}$ ICP-OES measurements reveal the $\mathrm{Ni} / \mathrm{Fe}$ ratio to be $3: 1$. ICP-OES measurements of $\mathrm{Cu}-\alpha-\mathrm{MnO}_{2}$ determine a copper amount of $3.42 \pm 0.16 \mathrm{wt}$ \% and a manganese amount of $39.89 \pm 0.11 \mathrm{wt}$. \% corresponding to the used ratio of precursor metals. Schemes of NiFe-LDH and $\mathrm{Cu}-\alpha-\mathrm{MnO}_{2}$ are depicted in Figure 1 a) and b) respectively. Detailed synthesis recipes are available in SI. The carbon component is necessary to increase the electrical conductivity and the accessible surface area of the tested electrocatalyst, especially of $\mathrm{Cu}-\alpha-$ $\mathrm{MnO}_{2}$. TEM images of the separately prepared catalyst materials show NiFe-LDH flakes tending to form agglomerates, making an accurate determination of thickness or size difficult (Figure 1a) and rod-like $\mathrm{Cu}$ $\alpha-\mathrm{MnO}_{2}$ nanoparticles supported on XC-72R, with a length of $100 \mathrm{~nm}$ and a width of $10 \mathrm{~nm}$ (Figure $1 \mathrm{~b}$ ). $\mathrm{X}$-Ray diffraction patterns of the prepared materials (Figure 2 a) relate to the literature known X-Ray diffraction patterns of pure tetragonal Cryptomelane-Q phase (Cu- $\alpha-\mathrm{MnO}_{2}$; JCPDS: 00-044-0141), Vulcan XC-72R and rhombohedral NiFe-LDH (JCPDS: 00-014-0191). The physical mixture shows a superposition of the separated components. 


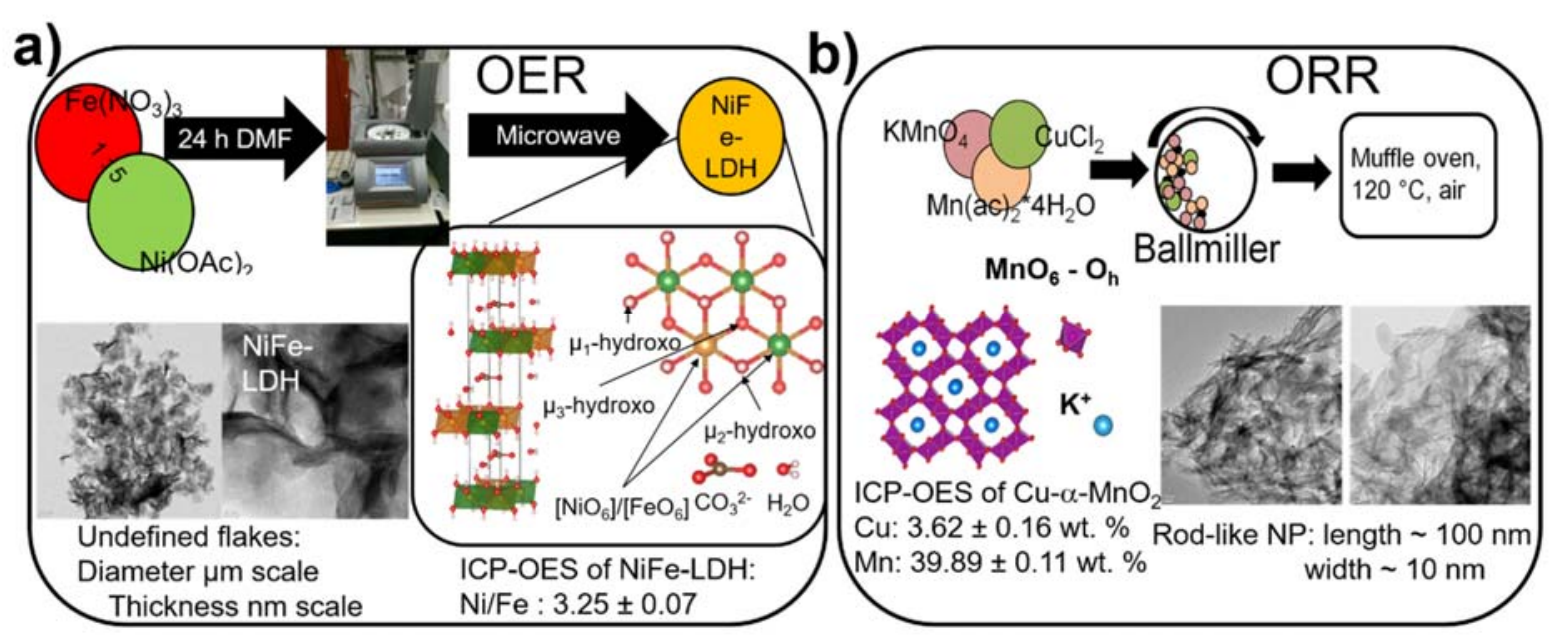

Figure 1. Basic concept of the herein introduced catalyst system consisting of two independent components.

a) Schematic Synthesis of NiFe-LDH including TEM images b) Synthesis scheme of $\mathrm{Cu}-\alpha-\mathrm{MnO}_{2}$ (copper doped cryptomelane type $\alpha-\mathrm{MnO}_{2}$ ).

To investigate the morphology of the prepared catalyst systems on the working electrode, $10 \mathrm{~mm}$ diameter cylindrical glassy carbon (GC) electrodes were drop coated using inks made of $\mathrm{Cu}-\alpha-\mathrm{MnO}_{2}$ supported on Vulcan XC-72R, of NiFe-LDH and of the combined Cu- $\alpha-\mathrm{MnO}_{2} / \mathrm{XC}-72 \mathrm{R} / \mathrm{NiFe}-\mathrm{LDH}$. The resulting SEM images represent the initial electrode surfaces before RDE tests. The electrodes prepared using the individual components separately showed identical features as described above for the TEM images. However, the electrodes coated by the three-component system revealed interesting and important unexpected features. Despite the low overall content of NiFe-LDH (20 wt. \%), $100 \%$ of the electrode surface is covered by the layered double hydroxide including the coverage of $\mathrm{XC}-72 \mathrm{R}$ supported $\mathrm{Cu}-\alpha-$ $\mathrm{MnO}_{2}$, determined by SEM (Figure 2d). The observed film morphology can be explained by means of surface charge -based electrostatic attraction. Measurements of the zeta potential of NiFe-LDH and $\mathrm{Cu}-\alpha-$ $\mathrm{MnO}_{2} / \mathrm{XC}-72 \mathrm{R}$ in the catalyst ink conditions revealed values of $11.34 \pm 0.81 \mathrm{mV}$ and $-9.23 \pm 0.42 \mathrm{mV}$, respectively. This finding is in good agreement with described coverage effects of $\gamma-\mathrm{MnO}_{2}$ and $\mathrm{NiFe}-$ $\mathrm{LDH}^{25}$ 

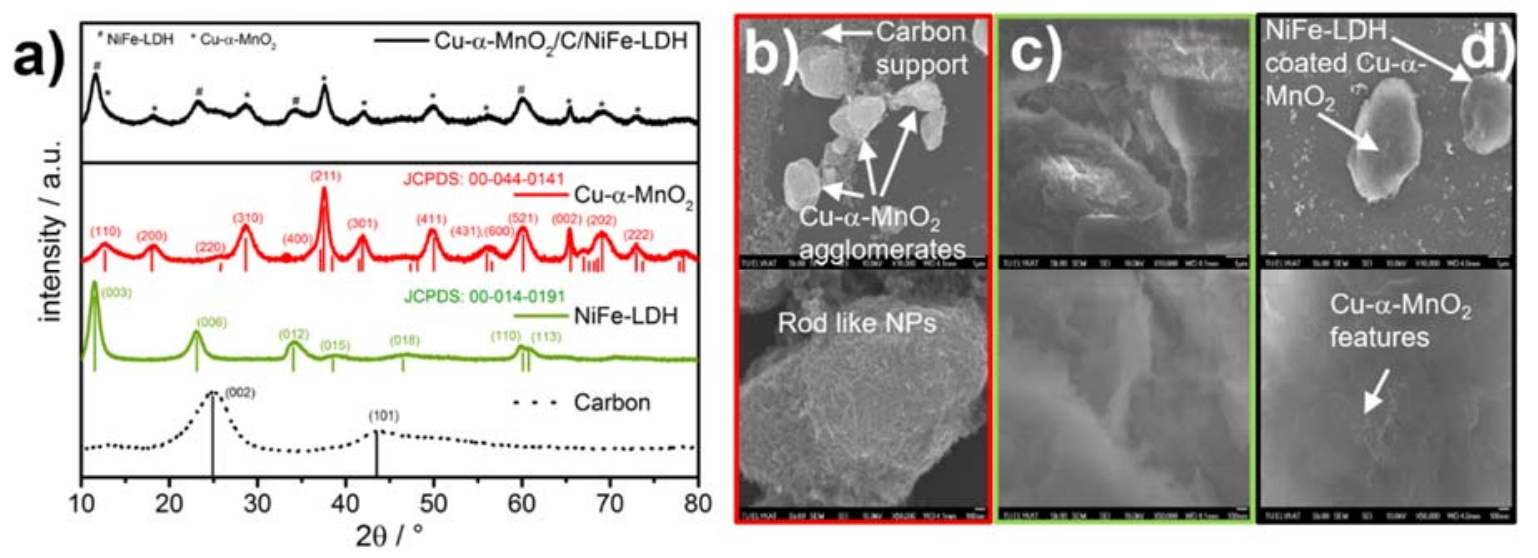

Figure 2. a) X-Ray diffraction patterns obtained with $\mathrm{Cu}-\mathrm{K} \alpha$ radiation. The lower part of a) shows the diffraction patterns of the separated components $\mathrm{Cu}-\alpha-\mathrm{MnO}_{2}$, Vulcan XC-72R and NiFe-LDH. The upper part depicts the physical mixture of the mentioned components. b-d) SEM images with different magnifications (upper row: $1 \mu \mathrm{m}$, lower row: $100 \mathrm{~nm}$ ) of (b) $\mathrm{Cu}-\alpha-\mathrm{MnO}_{2} @ \mathrm{XC}-72 \mathrm{R}$, (c) NiFe-LDH and (d) the physical mixture of $\mathrm{Cu}-\alpha-\mathrm{MnO}_{2}, \mathrm{XC}-72 \mathrm{R}$ and $\mathrm{NiFe}-\mathrm{LDH}$ (from left to right)

To investigate the role and influence of $\mathrm{Cu}$ on structure and reactivity of the ORR-active component, $\alpha$ $\mathrm{MnO}_{2}$ catalysts doped with $\mathrm{Cu}, \mathrm{Ni}$ and $\mathrm{Co}$ each with a share between 3.4 and $3.5 \mathrm{wt}$. \% were prepared and their physicochemical and electrochemical properties were compared. As shown in Figure 3, Co, Ni and $\mathrm{Cu}$ do not influence the crystal structure of $\alpha-\mathrm{MnO}_{2}$ (Figure $3 \mathrm{a}$ )). XPS was used to investigate the influence of $\mathrm{Cu}, \mathrm{Ni}$ and $\mathrm{Co}$ on the electronic surface state of $\alpha-\mathrm{MnO}_{2}$ (Figure $3 \mathrm{c}$ and $3 \mathrm{~d}$ ), in conjunction with different manganese oxides $\left(\mathrm{Mn}_{3} \mathrm{O}_{4}, \alpha-\mathrm{Mn}_{2} \mathrm{O}_{3}\right.$, commercial $\mathrm{MnO}_{2}$ and $\left.\alpha-\mathrm{MnO}_{2}\right)$. Conclusions on the $\mathrm{Mn}$ redox states are possible by observing the $\mathrm{Mn} 3 \mathrm{~s}$ multiplet splitting. Increasing oxidation states are accompanied by decreasing magnitude of peak splitting. The reference materials showed Mn 3s splitting in excellent agreement with literature references. ${ }^{29}$ Based on the Mn 3s multiplet splitting $(4.6 \mathrm{eV})$ in Figure $3 \mathrm{c}, \mathrm{Cu}-\alpha-$ $\mathrm{MnO}_{2}$ and $\alpha-\mathrm{MnO}_{2}$ were all in the oxidation state +4 . It is evident that copper in the catalyst material did not influence the manganese oxidation state, since $\mathrm{Cu}-\alpha-\mathrm{MnO}_{2}$ and $\alpha-\mathrm{MnO}_{2}$ reveal the same $\mathrm{Mn} 3 \mathrm{~s}$ multiplet splitting. The same observation was made for $\mathrm{Co}-\alpha-\mathrm{MnO}_{2}$ and $\mathrm{Ni}-\alpha-\mathrm{MnO}_{2}$, too, see Figure $3 \mathrm{~d}$. An influence of the dopants on the oxidation state and thus potentially on the electrocatalytic activity of $\alpha$ $\mathrm{MnO}_{2}$ can therefore be excluded. A synoptic view of all XPS data of the complete set of materials is given in SI.

Contact-free microwave cavity perturbation technique (MCPT) measurements were conducted to investigate the influence of the dopants on the electric conductivity of the materials. ${ }^{30,31}$ Setup and measurements are described in SI. A near-linear correlation between the measured electrode potential at - 
$3 \mathrm{~mA} \mathrm{~cm}-2$ and the electrical conductivity was uncovered (Figure 3b) highlighting that the dopants directly influence the electrical conductivity of the ORR catalysts. $\mathrm{Cu}-\alpha-\mathrm{MnO}_{2}$ revealed the highest electrical conductivity accompanied by the lowest overpotential to provide $-3 \mathrm{~mA} \mathrm{~cm} \mathrm{~cm}^{-2}$.
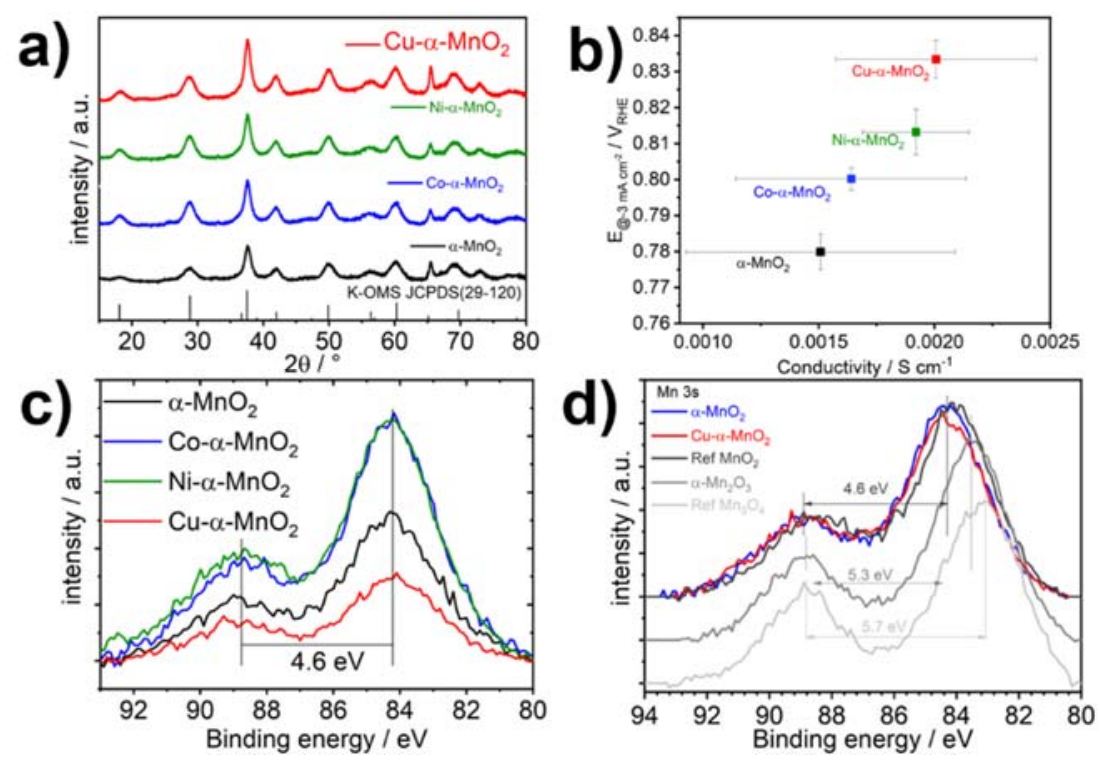

Figure 3. Physicochemical characterization of $\mathrm{M}-\alpha-\mathrm{MnO}_{2}(\mathrm{M}=-, \mathrm{Co}, \mathrm{Ni}, \mathrm{Cu})$. a) XRD measurements of $\mathrm{M}-\alpha-\mathrm{MnO}_{2}$ for the evaluation of the crystal structure. b) Correlation of potential to provide a current density of $-3 \mathrm{~mA} \mathrm{~cm}{ }^{-2}$ and the electrical conductivity measured by MCPT. c) XPS measurements of Mn 3s of M$\alpha-\mathrm{MnO}_{2}(\mathrm{M}=-, \mathrm{Co}, \mathrm{Ni}, \mathrm{Cu})$ to determine the influence of the dopant on the oxidation state. d) XPS measurements of Mn3s core level for the evaluation of the oxidation state of Mn, including measurements of reference materials: $\alpha-\mathrm{MnO}_{2}$, commercial $\mathrm{MnO}_{2}, \alpha-\mathrm{Mn}_{2} \mathrm{O}_{3}$ and $\mathrm{Mn}_{3} \mathrm{O}_{4}$.

\section{Electrochemical Characterization of modular bifunctional catalysts}

The electrocatalytic ORR and OER activities of the two individual active components of the modular URFC catalyst, $\mathrm{Cu}-\alpha-\mathrm{MnO}_{2} / \mathrm{Carbon} / \mathrm{NiFe}-\mathrm{LDH}$, were compared to those of physically mixed, commercial noble-metal reference catalysts (mixture of $20 \mathrm{wt} . \% \mathrm{Pt} / \mathrm{C}$ and $20 \mathrm{wt}$. \% Ir/C on Vulcan XC-72R) using a three-electrode rotating disk electrode (RDE) setup at a very low mass loading of only $0.2 \mathrm{mg} \mathrm{cm}^{-2}$ (Figure 4a). The reversible oxygen electro activity tests revealed previously unachieved electrocatalytic bifunctional ORR and OER activities, not only of the individual components $\mathrm{Cu}-\alpha-\mathrm{MnO}_{2} / \mathrm{XC}-72 \mathrm{R}$ and $\mathrm{NiFe}-$ LDH, respectively, but also of the combined URFC catalyst. More importantly, both materials displayed no significant activity for the respective reverse reaction (Figure 4a). The comparison between the modular 
$\mathrm{Cu}-\alpha-\mathrm{MnO}_{2} / \mathrm{XC}-72 \mathrm{R} / \mathrm{NiFe}-\mathrm{LDH}$ catalyst and the commercial Pt-Ir system in Figure 4 a) exhibited the full advantages of the modular catalyst in alkaline conditions. Tests of the electrocatalytic activity and stability of $\mathrm{Cu}-\alpha-\mathrm{MnO}_{2} / \mathrm{XC}-72 \mathrm{R} / \mathrm{NiFe}-\mathrm{LDH}$ under prolonged URFC cycling are depicted in Figure $\left.4 \mathrm{a}\right)-\mathrm{d}$ ). Despite the very low loadings of $\mathrm{Cu}-\alpha-\mathrm{MnO}_{2}$ of only $0.2 \mathrm{mg}_{\mathrm{cat}} \mathrm{cm}^{-2}$, the ORR activity of the three-component system exceeded all noble metal reference catalysts. Given the negligible ORR activity drop, significant detrimental cross talk between NiFe-LDH and the $\mathrm{Cu}-\alpha-\mathrm{MnO}_{2}$ affecting the ORR activity can be excluded. On the other hand, the OER activity of the investigated system actually increased compared to the pure $\mathrm{NiFe}-\mathrm{LDH}$ component performance. Based on the more pronounced $\mathrm{Ni}^{2+/ 3+}$ redox features, we believe this increase in OER activity was caused by enhanced conductivity and more accessible surface area thanks to the carbon support. ${ }^{32,33}$ To some extend $\mathrm{Cu}-\alpha-\mathrm{MnO}_{2} / \mathrm{XC}-72 \mathrm{R}$ contributes at high anodic potentials to the overall OER currents. Although the PGM reference catalyst showed more anodic, which is more beneficial, ORR onset potentials in Figure 4a, the potential necessary to supply $-3 \mathrm{~mA} \mathrm{~cm}{ }^{-2}$ was comparable for that of the three-component URFC catalyst. By contrast, $\mathrm{Cu}-\alpha-\mathrm{MnO}_{2} / \mathrm{XC}-72 \mathrm{R} / \mathrm{NiFe}-\mathrm{LDH}$ showed more a more beneficial cathodic onset potentials for the OER as well as lower stationary potentials at $+10 \mathrm{~mA} \mathrm{~cm}-2$ indicating higher OER activities. The influence of $0.5 \mathrm{M} \mathrm{NaCl}$ on the catalytic reactivity of the material is depicted in SI (Figure S13). 

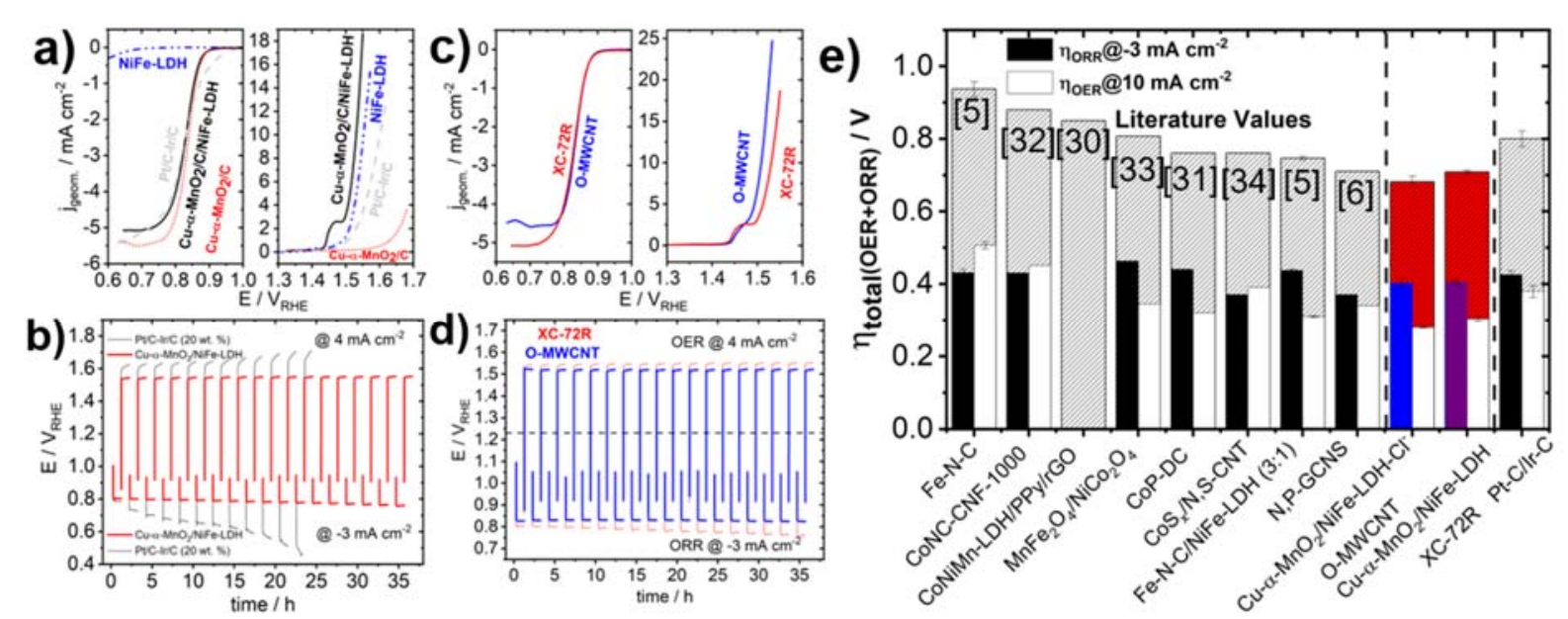

Figure 4. Evaluation of the bi functional electrocatalytic performance: a) Comparison of the modular 3component $\mathrm{Cu}-\alpha-\mathrm{MnO}_{2} / \mathrm{XC}-72 \mathrm{R} / \mathrm{NiFe}-\mathrm{LDH}$ catalyst, the respective individual component, and the noble metal reference Pt-C/Ir-C (both 20 wt. \% at C). b) Galvanostatic measurements of the electrocatalytic stability of $\mathrm{Cu}-\alpha-\mathrm{MnO}_{2} / \mathrm{XC}-72 \mathrm{R} / \mathrm{NiFe}-\mathrm{LDH}$ compared with the noble metal reference system c) Initial electrocatalytic activity of the primary material $\left(\mathrm{Cu}-\alpha-\mathrm{MnO}_{2} / \mathrm{XC}-72 \mathrm{R} / \mathrm{NiFe}-\mathrm{LDH}\right)$ compared with the modified material $\left(\mathrm{Cu}-\alpha-\mathrm{MnO}_{2} / \mathrm{O}-\mathrm{MWCNTs} / \mathrm{NiFe}-\mathrm{LDH}_{-}-\mathrm{Cl}^{-}\right)$and d) comparison of the galvanostatic stability of the primary material (XC-72R) and the modified material (O-MWCNT). The depicted measurements are conducted in $\mathrm{O}_{2}$ saturated $0.1 \mathrm{M} \mathrm{KOH}$ at RT and $1600 \mathrm{rpm}$, the LSVs are measured at a scan rate of $5 \mathrm{mV} \mathrm{s}$. e) Contrasting juxtaposition of the prepared catalyst systems with literature reported catalyst systems. ${ }^{7-14}$ All catalyst loadings are at $0.2 \mathrm{mg} \mathrm{cm}-2$.

To demonstrate the power of the modular catalyst design, we introduced chemical modifications to two out of the three catalyst components. First, we replaced the graphitized carbon with an oxidized carbon nanotube support yielding the URFC catalyst $\mathrm{Cu}-\alpha-\mathrm{MnO}_{2} / \mathrm{O}-\mathrm{MWCNTs} / \mathrm{NiFe}-\mathrm{LDH}$, labelled "OMWCNT" in Figure 4 c) and d). Oxidized MWCNTs are significantly more stable support materials, and contribute to OER and ORR reactivity. Then, we further modified the OER active component NiFe-LDH using anion exchange, without affecting the physicochemical and electrochemical properties of the other component (see detailed characterization of the $\mathrm{Cu}-\alpha-\mathrm{MnO}_{2} / \mathrm{O}-\mathrm{MWCNTs} / \mathrm{NiFe}-\mathrm{LDH}-\mathrm{Cl}^{-}$URFC catalyst in Figures S5-S12).

The electrochemical evaluation of the modified URFC catalyst $\left(\mathrm{Cu}-\alpha-\mathrm{MnO}_{2} / \mathrm{O}-\mathrm{MWCNTs} / \mathrm{NiFe}-\mathrm{LDH}-\right.$ $\mathrm{Cl}^{-}$) is depicted in Figure $4 \mathrm{c}$ ). As expected, the modified catalyst did not show any improvement in ORR activity. However, the OER activity is significantly improved compared to the unmodified catalyst system. 
The generated current density at applied electrode potential as well as the measured potential at $+10 \mathrm{~mA}$ $\mathrm{cm}^{-2}$ are superior for $\mathrm{Cu}-\alpha-\mathrm{MnO}_{2} / \mathrm{O}-\mathrm{MWCNTs} / \mathrm{NiFe}-\mathrm{LDH}-\mathrm{Cl}^{-}$. The effective over-potential $\eta_{\text {total }}=\eta_{\text {OER }}+$ $\eta_{\text {ORR }}$ at $+10 \mathrm{~mA} \mathrm{~cm}^{-2}\left(\eta_{\text {OER }}\right)$ and at $-3 \mathrm{~mA} \mathrm{~cm}^{-2}\left(\eta_{\text {ORR }}\right)$ is plotted in Figure 4 e). Our starting URFC catalyst $\left(\mathrm{Cu}-\alpha-\mathrm{MnO}_{2} / \mathrm{XC}-72 \mathrm{R} / \mathrm{NiFe}-\mathrm{LDH}\right)$ reached a $\eta_{\text {total }}$ of $0.709 \mathrm{~V} \pm 0.001 \mathrm{~V}$ outperforming the commercial noble-metal reference catalyst by $90 \mathrm{mV}$. The $\mathrm{Cu}-\alpha-\mathrm{MnO}_{2} / \mathrm{O}-\mathrm{MWCNTs} / \mathrm{NiFe}-\mathrm{LDH}-\mathrm{Cl}^{-}$catalyst displayed a mere $0.682 \pm 0.015 \mathrm{~V}$ outperforming all previous bi-functional catalysts reported to date (Figure $4 \mathrm{e}$ )). We note that the use of further improved ORR components such as N,P-GCNS and CoSx/N, S-CNT in our modular approach could push the performance even higher. ${ }^{8}$ Galvanostatic stability measurements revealed the superiority of our URFC catalyst further (Figure $4 \mathrm{~b}$ and d). The lower electrode potential swings mitigated degradation leading to a clearly more stable catalyst system with a decrease in performance of only $0.0002 \mathrm{~V} \mathrm{~h}^{-1}(\mathrm{O}-\mathrm{MWCNTs})$ compared to $0.0178 \mathrm{~V} \mathrm{~h}^{-1}$ (Pt-C/Ir-C reference) and $0.0016 \mathrm{~V} \mathrm{~h}^{-1}$ (Cu- $\alpha$ $\mathrm{MnO}_{2} / \mathrm{XC}-72 \mathrm{R} / \mathrm{NiFe}-\mathrm{LDH}$ ) to supply the applied current densities. Lower electrode swings in alternating ORR/OER strain is especially an issue regarding carbon corrosion. All the catalysts compared contain a carbon component, but the potentials that are required providing the applied OER current range are different. The more active the material, the lower the applied potential, as a result of which a significant improvement is achieved with regard to the material stress and degradation can be minimized. Graphitized carbons, e.g. carbon nanotubes MWCNTs are significantly more stable than other carbon materials. This becomes clear in Figure $4 \mathrm{~d}$ ). The significantly improved degradation is due to the significantly more stable carbon material. Nevertheless, in order to maintain the applied currents, potentials above $1.3 \mathrm{~V}$ must be applied in any case, which is viewed as critical for carbon corrosion. Therefore, $0.0002 \mathrm{~V} \mathrm{~h}^{-1}$ increase in voltage is remarkable in the case of the labeled O-MWCNT catalyst. ${ }^{5,6}$

To investigate the catalyst performance in URFC single cell conditions, single cell unitized regenerative fuel cell (URFC) measurements were performed as depicted in Figure 5. Tests started with ORR polarization.
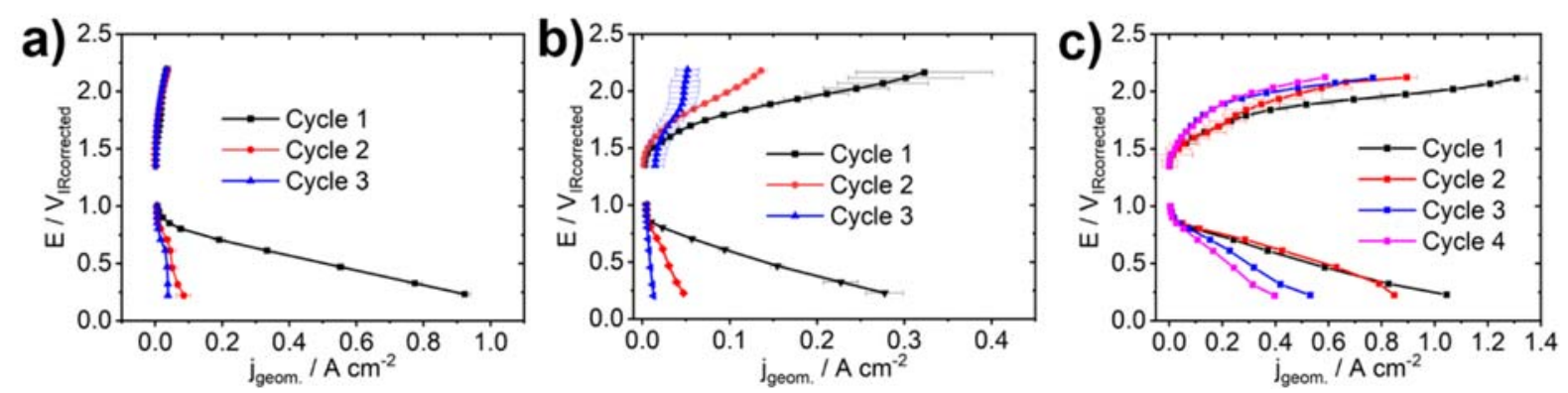

Figure 5. URFC measurements of the prepared modular catalyst compared with noble metal reference catalyst. a) Full cell measurements of commercial Pt-C/Ir-C (both 20 wt. \% at Carbon support). b) and c) 
$\mathrm{Cu}-\alpha-\mathrm{MnO}_{2} / \mathrm{XC}-72 \mathrm{R} / \mathrm{NiFe}-\mathrm{LDH}$ as oxygen electrode with different step times of the applied potential. The fuel cell polarization curves were measured with $250 \mathrm{~mL} \mathrm{H}_{2} \mathrm{~h}^{-1}$ and $500 \mathrm{~mL} \mathrm{O}_{2} \mathrm{~h}^{-1}$ at $50{ }^{\circ} \mathrm{C}$ with a relative humidity $(\mathrm{RH})$ of $100 \%$. Water electrolysis measurements were conducted in $0.1 \mathrm{M} \mathrm{KOH}$ at $50{ }^{\circ} \mathrm{C}$.

The PGM reference catalyst showed excellent initial fuel cell activity, yet poor electrolysis performance. The stability of the Pt-C/Ir-C (both 20 wt. \% at C) was poor, as well, judged by a significant decrease in fuel cell performance after one electrolysis cycle. Figure $5 \mathrm{~b}$ and $5 \mathrm{c}$ show cell measurements of the modular $\mathrm{Cu}-\alpha-\mathrm{MnO}_{2} / \mathrm{XC}-72 \mathrm{R} / \mathrm{NiFe}-\mathrm{LDH}(2: 2: 1)$ catalyst. While the initial fuel cell performance of $\mathrm{Cu}-\alpha-$ $\mathrm{MnO}_{2} / \mathrm{XC}-72 \mathrm{R} / \mathrm{NiFe}-\mathrm{LDH}$ was somewhat lower than the reference, its performance during water electrolysis surpassed the reference significantly. Experimental error bars reflect degradation phenomena. The inset of Figure 5 evidences that the degradation is mainly due to the high oxidative potentials $\left(>1.8 \mathrm{~V}_{\text {cell }}\right.$ potential). To mitigate oxidative degradation current hold times were adjusted (Figure 5c). Now, the initial fuel cell and electrolysis performance meet and outperform the PGM reference. Invariably, the performance decreases somewhat after each cycle. Degradation appears to be highly affected by time, exposure to oxidative OER relevant potentials as well as the cell reversal challenging the membrane by changing the operating modes accompanied by anion moving direction.

We have introduced the concept of a modular three-component bi-functional catalyst design for use at oxygen electrodes of URFC systems. Unlike previous catalyst designs, the modularity enables an independent optimization of each functional component. We demonstrated the modular flexibility of our three component catalysts by optimizing two out of the three catalyst components resulting in improved oxygen reactivity and stability. Component innovations of the $\mathrm{Cu}-\alpha-\mathrm{MnO}_{2} / \mathrm{XC} 72 \mathrm{R} / \mathrm{NiFe}-\mathrm{LDH}-\mathrm{Cl}$ - and the $\mathrm{Cu}-\alpha-\mathrm{MnO}_{2} / \mathrm{O}-\mathrm{MWCNTs} / \mathrm{NiFe}-\mathrm{LDH}-\mathrm{Cl}$ - include the $\mathrm{Cu}$-based stabilization of redox-active and ORR catalytically active $\mathrm{Mn}$ centers of a previously overlooked $\alpha-\mathrm{MnO}_{2}$ phase, the use of anion exchanged OER active LDH phase, as well as a corrosion stable carbon nanotube component. The combined ORR/OER over-potential amounts to a previously unarchived value of $0.682 \pm 0.015 \mathrm{~V}$. This represents an improvement of $20 \mathrm{mV}$ compared to the initial $\mathrm{Cu}-\alpha-\mathrm{MnO}_{2} / \mathrm{XC}-72 \mathrm{R} / \mathrm{NiFe}-\mathrm{LDH}$ catalyst. Further modifications of the ORR component are predicted in further boosting overall activity. High ionic transport demands on the membrane and related losses highlight the need for concomitant research on catalyst materials and suitable reversible ion exchange membranes. 


\section{ASSOCIATED CONTENT \\ Supporting Information}

The Supporting Information is available free of charge on the ACS Publications website at DOI: XXXX A description of the material, electrochemical and physicochemical characterization including calculations are included in the SI.

\section{AUTHOR INFORMATION}

Corresponding Author

*Peter Strasser: pstrasser@tu-berlin.de

\section{ORCID:}

Peter Strasser: 0000-0002-3884-436X

\section{Notes}

The authors declare no competing financial interest.

\section{Acknowledgement}

Financial support by the German Research Foundation (DFG) through Grant Reference Number STR 596/12-1 and the federal ministry for economic affairs and energy (Bundesministerium für Wirtschaft und Energie, BMWi) under Grant Number 03EIV041F in the collaborative research project "MethQuest" in the group "MethFuel" are gratefully acknowledged.

\section{Literature}

1 Turner, J. et al. Renewable hydrogen production. International Journal of Energy Research 32, 379-407, doi:10.1002/er.1372 (2008).

2 Gasteiger, H. A., Kocha, S. S., Sompalli, B. \& Wagner, F. T. Activity benchmarks and requirements for Pt, Pt-alloy, and non-Pt oxygen reduction catalysts for PEMFCs. Applied Catalysis B: Environmental 56, 9-35, doi:10.1016/j.apcatb.2004.06.021 (2005).

3 McCrory, C. C., Jung, S., Peters, J. C. \& Jaramillo, T. F. Benchmarking heterogeneous electrocatalysts for the oxygen evolution reaction. J Am Chem Soc 135, 16977-16987, doi:10.1021/ja407115p (2013).

4 Osgood, H., Devaguptapu, S. V., Xu, H., Cho, J. \& Wu, G. Transition metal (Fe, Co, Ni, and Mn) oxides for oxygen reduction and evolution bifunctional catalysts in alkaline media. Nano Today 11, 601-625, doi:10.1016/j.nantod.2016.09.001 (2016).

5 Gupta, S. et al. Quaternary FeCoNiMn-Based Nanocarbon Electrocatalysts for Bifunctional Oxygen Reduction and Evolution: Promotional Role of Mn Doping in Stabilizing Carbon. ACS Catalysis 7, 8386-8393, doi:10.1021/acscatal.7b02949 (2017).

6 Chen, M. et al. Nanocarbon/oxide composite catalysts for bifunctional oxygen reduction and evolution in reversible alkaline fuel cells: A mini review. Journal of Power Sources 375, 277-290, doi:10.1016/j.jpowsour.2017.08.062 (2018).

7 Dresp, S. et al. An efficient bifunctional two-component catalyst for oxygen reduction and oxygen evolution in reversible fuel cells, electrolyzers and rechargeable air electrodes. Energy \& Environmental Science 9, 2020-2024, doi:10.1039/c6ee01046f (2016). 
Li, R., Wei, Z. \& Gou, X. Nitrogen and Phosphorus Dual-Doped Graphene/Carbon Nanosheets as Bifunctional Electrocatalysts for Oxygen Reduction and Evolution. ACS Catalysis 5, 4133-4142, doi:10.1021/acscatal.5b00601 (2015).

9 Li, W. et al. Advanced Bifunctional Oxygen Reduction and Evolution Electrocatalyst Derived from Surface-Mounted Metal-Organic Frameworks. Angew Chem Int Ed Engl 59, 5837-5843, doi:10.1002/anie.201916507 (2020).

10 Zhang, W. et al. ZIF-8/ZIF-67-Derived Co-Nx -Embedded 1D Porous Carbon Nanofibers with Graphitic Carbon-Encased Co Nanoparticles as an Efficient Bifunctional Electrocatalyst. Small 14, e1800423, doi:10.1002/smll.201800423 (2018).

11 Zhang, Y.-Q. et al. A strongly cooperative spinel nanohybrid as an efficient bifunctional oxygen electrocatalyst for oxygen reduction reaction and oxygen evolution reaction. Applied Catalysis B: Environmental 236, 413-419, doi:10.1016/j.apcatb.2018.05.047 (2018).

$12 \mathrm{Hu}, \mathrm{C}$. et al. Urchin-like non-precious-metal bifunctional oxygen electrocatalysts: Boosting the catalytic activity via the In-situ growth of heteroatom (N, S)-doped carbon nanotube on mesoporous cobalt sulfide/carbon spheres. J Colloid Interface Sci 524, 465-474, doi:10.1016/j.jcis.2018.04.052 (2018).

13 Jia, X. et al. Fabrication and Bifunctional Electrocatalytic Performance of Ternary CoNiMn Layered Double Hydroxides/Polypyrrole/Reduced Graphene Oxide Composite for Oxygen Reduction and Evolution Reactions. Electrochimica Acta 245, 59-68, doi:10.1016/j.electacta.2017.05.120 (2017).

14 Lin, Y. et al. Defective Carbon-CoP Nanoparticles Hybrids with Interfacial Charges Polarization for Efficient Bifunctional Oxygen Electrocatalysis. Advanced Energy Materials 8, 1703623, doi:10.1002/aenm.201703623 (2018).

15 Yi, Y. et al. Electrochemical corrosion of a glassy carbon electrode. Catalysis Today 295, 32-40, doi:10.1016/j.cattod.2017.07.013 (2017).

16 Hasche, F., Oezaslan, M. \& Strasser, P. Activity, stability and degradation of multi walled carbon nanotube (MWCNT) supported Pt fuel cell electrocatalysts. Phys Chem Chem Phys 12, 1525115258, doi:10.1039/c0cp00609b (2010).

17 Mayrhofer, K. J. J. et al. Fuel cell catalyst degradation on the nanoscale. Electrochemistry Communications 10, 1144-1147, doi:10.1016/j.elecom.2008.05.032 (2008).

18 Strasser, P. \& Kühl, S. Dealloyed Pt-based core-shell oxygen reduction electrocatalysts. Nano Energy 29, 166-177, doi:10.1016/j.nanoen.2016.04.047 (2016).

19 Reier, T., Nong, H. N., Teschner, D., Schlögl, R. \& Strasser, P. Electrocatalytic Oxygen Evolution Reaction in Acidic Environments - Reaction Mechanisms and Catalysts. Advanced Energy Materials 7, 1601275, doi:10.1002/aenm.201601275 (2017).

20 Kibsgaard, J. \& Chorkendorff, I. Considerations for the scaling-up of water splitting catalysts. Nature Energy 4, 430-433, doi:10.1038/s41560-019-0407-1 (2019).

21 Gorlin, Y. \& Jaramillo, T. F. A Bifunctional nonprecious metal catalyst for ORR and OER. $J$ Am Chem Soc 132, 13612-13614 (2010).

Ghosh, S. et al. Microwave-assisted synthesis of porous $\mathrm{Mn}_{2} \mathrm{O}_{3}$ nanoballs as bifunctional electrocatalyst for oxygen reduction and evolution reaction. Catal. Sci. Technol. 6, 1417-1429, doi:10.1039/c5cy01264c (2016).

23 Ding, Y. et al. Synthesis and Catalyitic Activity of Cryptomelane-Type Manganese Dioxide Nanomaterials produced by a novel Solvent-Free Method. Chem. Mater. 17, 5382-5389 (2005).

24 Dresp, S. et al. Direct Electrolytic Splitting of Seawater: Activity, Selectivity, Degradation, and Recovery Studied from the Molecular Catalyst Structure to the Electrolyzer Cell Level. Advanced Energy Materials 8, 1800338, doi:10.1002/aenm.201800338 (2018).

25 Flegler, A., Müssig, S., Prieschl, J., Mandel, K. \& Sextl, G. Towards core-shell bifunctional catalyst particles for aqueous metal-air batteries: NiFe-layered double hydroxide nanoparticle coatings on $\gamma$-MnO 2 microparticles. Electrochimica Acta 231, 216-222, doi:10.1016/j.electacta.2017.01.179 (2017). 
26 Yi, Y. et al. Electrochemical Degradation of Multiwall Carbon Nanotubes at High Anodic Potential for Oxygen Evolution in Acidic Media. ChemElectroChem 2, 1929 - 1937, doi:10.1002/ (2015).

27 Song, F. \& Hu, X. Exfoliation of layered double hydroxides for enhanced oxygen evolution catalysis. Nat Commun 5, 4477, doi:10.1038/ncomms5477 (2014).

28 Yun-Shuan Ding et al. Synthesis and Catalyitic Activity of Cryptomelane-Type Manganese Dioxide Nanomaterials produced by a novel Solvent-Free Method. Chem. Mater. 17, 5382-5389 (2005).

29 Jr., J. L. J. a. M. F. H. Manganese (II) Oxidation at Mineral Surfaces: A Mircoscopic and Sprectroscopic Study. Geochimica et Cosmochimica Acta 58, 4985-4999 (1994).

30 Davis, D. J. et al. Role of $\mathrm{Cu}-\mathrm{Ion}$ Doping in $\mathrm{Cu}-\alpha-\mathrm{MnO} 2$ Nanowire Electrocatalysts for the Oxygen Reduction Reaction. The Journal of Physical Chemistry C 118, 17342-17350, doi:10.1021/jp5039865 (2014).

31 Lambert, T. N. et al. Understanding the Effects of Cationic Dopants on $\alpha-\mathrm{MnO} 2$ Oxygen Reduction Reaction Electrocatalysis. The Journal of Physical Chemistry C 121, 2789-2797, doi:10.1021/acs.jpcc.6b11252 (2017).

32 Trotochaud, L., Young, S. L., Ranney, J. K. \& Boettcher, S. W. Nickel-iron oxyhydroxide oxygenevolution electrocatalysts: the role of intentional and incidental iron incorporation. J Am Chem Soc 136, 6744-6753, doi:10.1021/ja502379c (2014).

33 Trotochaud, L., Ranney, J. K., Williams, K. N. \& Boettcher, S. W. Solution-cast metal oxide thin film electrocatalysts for oxygen evolution. $J$ Am Chem Soc 134, 17253-17261, doi:10.1021/ja307507a (2012). 


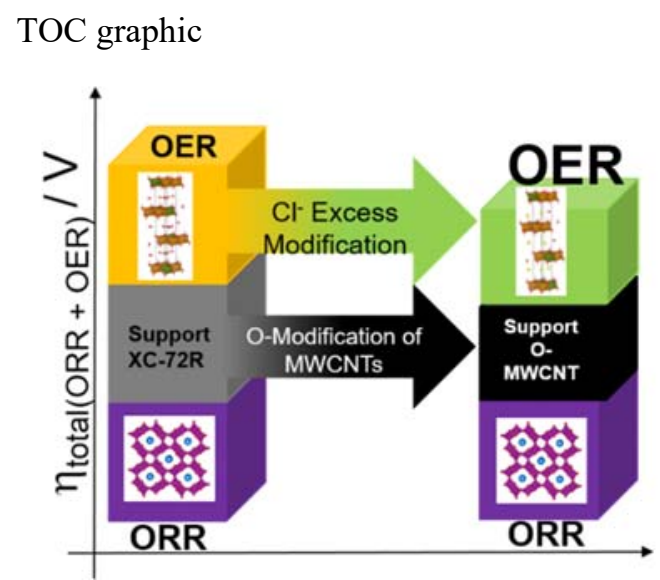

